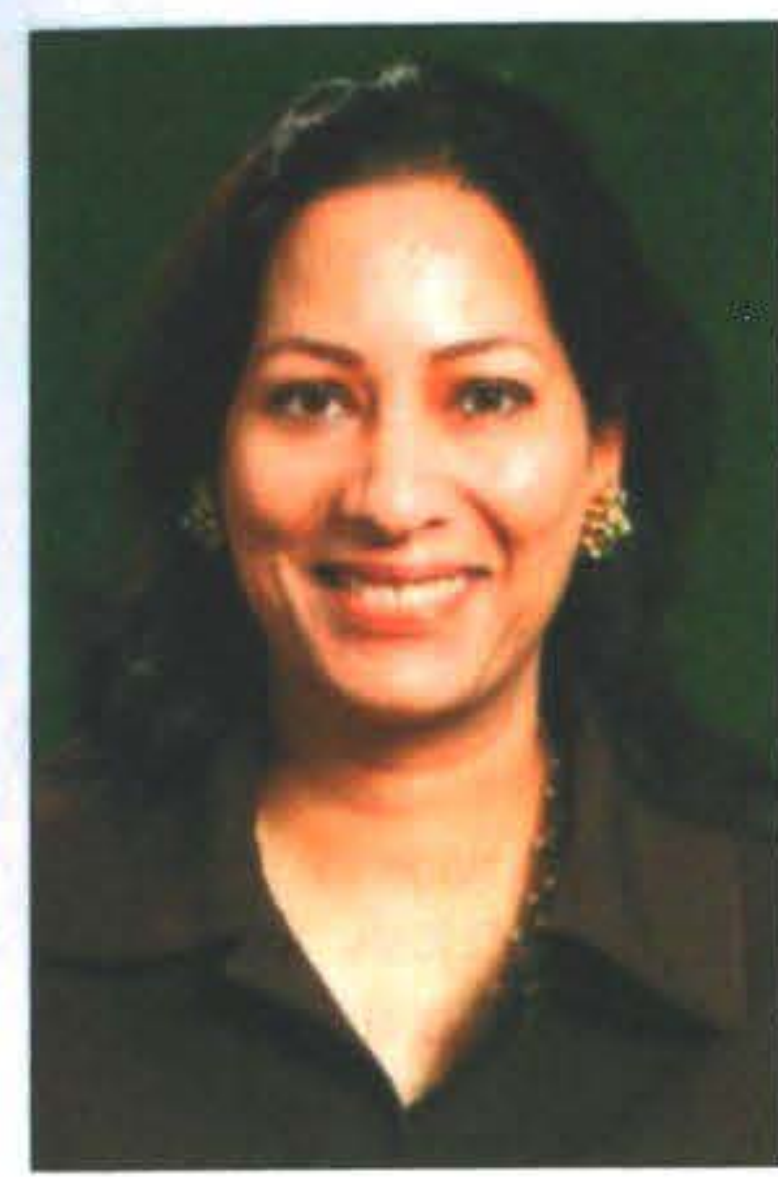

\title{
MIGRATION AND DEVELOPMENT: A FRAMEWORK TO IDENTIFY THE LINKS, POLICIES AND INSTITUTIONS THAT MATTER
}

\author{
Manjula Luthria \\ Pacific Region, World Bank
}

\begin{abstract}
It is estimated that the gains to global welfare from a modest increase in migration greatly outweigh the gains to welfare from any further trade liberalization. Yet, migration remains an ill-understood and under-researched instrument of development. In fact, only recently has the liberalization of labour markets been discussed in the same policy-oriented way as the liberalization of goods or capital markets.

This address will present an analytical framework for thinking about economic migration and explore the channels through which development outcomes eventuate. It will distinguish between permanent and temporary migration flows and outline the policy challenges faced in both forms of movements. Both sending and receiving countries have a role to play in ensuring that migration policies are development friendly while remaining market-driven. In particular, it will highlight the market failures that plague the temporary movement of people and keep such movements at sub-optimal levels world-wide. These market failures are particularly onerous for the small fragile states of the Pacific that seek to improve the economic outcomes of their citizens through regional integration but are faced with the challenges of geography and size. Given the importance of promoting more pro-poor migration globally and in the Pacific, this keynote will outline the policy and institutional underpinnings that are needed to facilitate temporary programs for the poor.
\end{abstract}

\section{Introduction}

There is strong evidence now showing that labor market restrictions are imposing a much greater burden on the global economy than the remaining trade restrictions. Through general equilibrium models it has been estimated that complete and free migration of labor could double global incomes whereas a feasible increase in migration would increase income worldwide by $\$ 772$ billion in $2025^{1}$. When correcting for price changes faced and caused by these movements, the gains approximate to $\$ 356$ billion which is a $0.6 \%$ increase in global income. Lest we dismiss this is too small, it helps to note that this figure is about three times all official development assistance and dwarfs the expected gains from all remaining trade liberalization. This increase would also translate into a slightly more favorable distribution for developing countries as their share of aggregate gain is 1.8 percent, whereas the gain to native high-income countries is 0.4 percent relative to the baseline.

What are the channels through which these labour mobility related welfare gains and losses work themselves through the economy? The main aim of this paper is to identify those channels of influence using a production-function framework to position the analytic arguments and empirical findings where available.

\section{Analytical Framework, Empirical Findings and Policy Implications}

The framework adopted here follows a traditional 'production function' approach where improvements in economic welfare can be thought of as resulting from movements along the production function or from pushing out the production frontier. These movements can occur for any of the following reasons: (i) there has been an increase in the amount of total resources available - either labour or capital resources, (ii) there is an improvement in the way resources are combined or allocated (iii) externalities emerge from migration which can be captured. I use this to organize the analytic and empirical findings for both, migrant-sending as well as migrant-receiving countries. 


\section{A. Migrant-sending point of view (Pacific)}

\section{i) Increase in amount of resources available}

Remittances are monies or goods sent home to family members or communities by migrants that live and work in other countries. The export of labor results in a national loss of the abundant factor but frequently results in an inflow of capital through remittances. In a simple world, if the productivity of labor is low in labor abundant countries, then an injection of capital through remittances should improve the productivity of labor that remains behind by virtue of it being combined with more productive capital. If there is an improvement in labor market conditions due to the departure of some excess labor then that would further increase the benefits to domestic resident labor. And if these additional capital resources respond positively to adverse economic conditions (i.e. are counter cyclical) as they are often presumed to be, then the injection is even more precious because it comes at a time when the country needs it most - unlike private capital which may pull out in adverse times and make bad economic conditions worse. ${ }^{2}$ To add to this, there may be multiplier effects if the economy is demand-constrained and remittances could increase the output of many sectors.

The impact of remittances of migrant-sending communities is not trivial and evidence is growing worldwide that remittances have had a deep and far reaching positive impact on immediate household members as well as broader communities. In an effort to understand the size and impact of remittances in the Pacific we commissioned household level surveys in Fiji and Tonga where over 900 households answered detailed questions on their household characteristics, migration behavior, size and frequency of remittances, the household's spending patterns and broader socio-economic status. ${ }^{3}$ These surveys have been analyzed and have pointed to the following main results that show that:

\section{$\bullet$}

The amount of resources received in these countries through remittances are significant. In Tonga, over $90 \%$ of the households surveyed received remittances in comparison with $43 \%$ of households in the Fijian sample. Among remittance receivers, Tongan households receive and average of US3,067 in comparison with US1,328 in Fiji.

The positive impact of remittances on poverty reduction is strong using a variety of measures of deprivation. After taking remittances into account, all measures of relative deprivation improve, with different intensities in rural and urban areas.

However, it would be too simplistic to assume that that the loss of one resource - labor, is fully compensated for by an increase in another resource - capital, and I will return to this issue again. From the perspective of assessing the impact of increased resources on the economy, at least three questions come to mind which point to the potentially negative effects of remittances.

Do remittances suffer from the problems associated with resource rents? This refers to the "curse of natural resources" where windfall gains from natural resources like oil or timber have tended to impede governance and modernization in most countries by taking away the pressures that push for broad-based growth. There are at least two very fundamental differences between remittances and resource revenues which should lead to very different outcomes. First, natural resource income is of a large magnitude and highly concentrated in the hands of a few, creating a pocket of powerful rent-seekers whereas remittances are small and widely dispersed in the country; and second, remittances avoid the government as middleman which resource-rents cannot, thus allowing the middleman to follow arbitrary policies which may promote corruption and retard growth.

Are remittance inflows akin to aid inflows which also increase capital resources available to a country? In particular, can remittances cause inflation, overvaluation of the exchange rate and render the tradable sector uncompetitive? Economists call this the "Dutch disease" where the effect of large inflows of foreign exchange is that the exchange rate appreciates making exports uncompetitive in world markets hence doing a disservice to productive sectors in general. The difference however is that typically remittances are small and grow slowly over time making the effects also small and the time period long enough to allow other sectors to adjust. Where this is not the case, and Fiji (rather than Tonga or Samoa) may fit that description recently, there is the possibility of adverse impacts of exchange rate appreciations. Overall however, aid and remittances are not to be equated. Whereas aid is an external injection into the economy and raises all sorts of questions about ownership, capacity, and governance remittances are not really that different from any other export income for its citizens where the export is the service being performed outside of the national borders. In fact, when remittances are treated as income in the calculation of debt/GDP and debt/export income ratios of countries, these ratios drop quite significantly thus raising the creditworthiness of these countries in international financial markets and further improving access to capital (World Bank, 2006, p. 102).

The third question relates to the impact of remittances on household labor supply. Do households that receive remittances work less? Economists call this the "backward bending supply curve" response where increased income does not cause more labor to be forthcoming and individuals choose leisure instead or work. ${ }^{4}$ It is possible that remittance receiving members of the household may raise their reservation wage and prefer to stay out of the labor market but the evidence from Philippines, Guatemala and Jamaica shows that remittance receiving households tend to invest more in education, i.e. opt for more schooling 
instead of working early; as well as show evidence of reduction in child labor and an increase in self-employment. Similar evidence from the Pacific is discussed in the next section which pertains to the decisions surrounding the allocation of resources.

\section{Policy implications}

Can policy help increase the inflow of remittances? Since remittances are essentially a person-to-person transfer shaped by family ties and shared cultural values, it is hard to think of policy measures that make migrants send more money home. While the flow of remittances will vary with the changing circumstances of individuals and families, a larger migrant stock would in general be correlated with larger remittances. Holding other parameters constant, temporary workers are also likely to remit more to their home countries than permanent workers, and this point is taken up later on

Beyond enhanced labor mobility in general, a reduction in the transaction cost of making financial transfers would ensure that recipients get most of what is sent to them. Evidence points to unduly high transaction costs in many corridors although global best practice puts it at about 3 percent. Further, the size of remittances is estimated to be highly elastic w.r.t. costs, hence a reduction in cost of one percent is likely to induce more than a $1 \%$ increase in remittances (Gibson, et al., 2006). A lowering of costs in the formal financial system, would also enable senders to use formal channels rather than informal channels -- such as mailing or personal deliveries -- and this would allow better data to be recorded and enable central banks to make necessary changes to monetary policy when needed.

\section{ii) Improvement in allocation of resources}

In addition to the static effects stemming from the increased remittance resources, migration may be able to influence the way resources are allocated, both at the aggregate level as well as at the level of the household. At the aggregate level, remittances can alter the allocation of resources among groups of households by changing the underlying distribution of income. At the micro level of the household, the prospect of migration and the subsequent receipt of remittances can have profound effects on the allocation of income towards consumption or investment. We take up these effects in turn.

In countries where the poor have migration options, remittances tend to benefit the poorest and hence result in reducing income inequalities. When the relatively well-off migrate, or where migration is skewed towards the highly skilled, income inequality may worsen. As income distribution changes, so does access to assets such as capital equipment or land and the final outcome of how labor, land and capital are combined in productive activities, but it has not been possible to empirically map out these effects yet.
In fact, even measuring income inequality itself poses some methodological challenges. Measures such as the Gini coefficient may remain unchanged despite the fact that the shape of the underlying distribution curve changes. Further, such measures cannot take into account the fact that different cohorts of people may go in and out of certain income quintiles making it necessary to use panel data which is very hard to come by. Through household survey data collected in the Pacific we are able to show that remittances and other unrequited internal transfers have a strong positive impact on income distribution. In Tonga, the poorest $40 \%$ of the population's share of cash income increases from $7.3 \%$ to $18.7 \%$, and the share of the richest $20 \%$ falls from almost $63 \%$ to less than $50 \%$. In Fiji the impact is also positive but weaker than in Tonga as one would expect given fewer remittance-receiving households, where the share of the poorest $40 \%$ increases from $9 \%$ to $11.6 \%$, and the share of the richest $20 \%$ of the population falls from $57.8 \%$ to $53.8 \%$.

At the individual or household level, several studies have looked for a direct link between remittances and the consumption-investment mix of household expenditures, and journalistic references to the issue have often criticized the preponderance of remittance-funded consumption. There are important reasons to question the validity of these views.

From a welfare perspective, an extra dollar of investment is only better than an extra dollar of present consumption if the marginal social value of investment is greater than its marginal private value. At low levels of income - or when there is great volatility of income - access to a steady and reliable source of income for poor vulnerable households serves an important social protection role. Very few policies and instruments are available that can claim to cushion the poorest in direct and effective ways like remittances have shown to be able to do. Also, if the life-cycle model of remittances captures the motivation behind remittances then it is useful to bear in mind that remittances are sent to parents first, siblings next, and only later dedicated to building a 'nest egg'(data collected in a 1993-4 survey of Tongan migrants in Australia fully support this pattern). Remittances sent to parents are a form of pension payment for the parents and one should fully expect to see pension payments being spent on consumption rather than investment (the investment has already occurred). Remittances sent to siblings tend to be devoted to meeting their educational needs which should not be viewed the same as consumption.

Of course, positive externalities can exist in investment expenditure and it is for this reason that it is considered desirable to see remittances funding investment. Efforts to identify the causal effect of remittances on investment often run into various problems. First, investment is correlated with the opportunities that exist, i.e. only countries with good investment climates should expect to see remittances fund investment. Second, when more enterprising 
households are the ones sending migrants high investment may be wrongly associated with high investment due to self-selection. Third, remittances are fungible and it is difficult to isolate their effects from those of other sources of income - simply asking how remittances are spent is unlikely to reveal the marginal effect of remittances on spending because remittances, even when spent on investment, are likely to free up the marginal dollars for consumption. This is why there is often a difference between anecdotal and survey data which show the average percentage of spending on consumption and econometric data which calculates the marginal propensities by modeling remittances as an exogenous positive shock to household income.

In the household surveys conducted in Fiji and Tonga, questions on savings were posed directly rather than attempting to deduce it from consumption expenditures. The results showed that in Fiji, $79 \%$ of those who had received remittances had saved, in comparison with $62 \%$ of those who had not. In Tonga, where over $90 \%$ of households had received remittances there is still a difference, albeit not as great, with $59 \%$ of those who received remittances having saved versus $52 \%$ in the case of those who had not received remittances. A relatively higher proportion of Indigenous-Fijians in the lowest two quintiles had saved and the mean levels of saving in these two groups were significantly higher than the levels for Indo-Fijians in the same income quintiles. This is consistent with the earlier observation that the Indigenous-Fijian households in the lower two quintiles received a much higher level of remittances than their Indo-Fijian counterparts. It would therefore seem that being in receipt of remittances at lower ends of the per capita income spectrum can make a significant difference to saving. The econometric analysis considered both the impact of remittances on saving and the influence of saving by the household on the levels of remittances it received. It was found that in both samples remittances had a strong impact on saving, especially among the Fiji sample where the estimated marginal propensity to save from remittances was $73.4 \%$. When the effect of remittances on saving was estimated for the two ethnic groups in Fiji it was found that the strong remittances effect on saving is associated with Indigenous-Fijian households. The analysis also found that in Indigenous-Fijian households this relationship runs in both directions, indicating that migrants have a higher propensity to remit when the household saves more.

In Tonga evidence is also found that migration and remittances tend to increase income from non-wage sources such as business or farm income. This means that households with migrants are able to direct resources towards business activity. Tongan migrant households very often have their members spread across a number of activities and can act as a stimulus and conduit for business activity acting as 'transnational corporations of kin'. The Fijian results do not tell a similar story, perhaps because the remittances are still a relatively early phenomenon, are smaller, and are engaged in different occupations from their Tongan counterparts.

Savings and investment may also take different forms. Income spent on building human capital should be viewed as investment rather than consumption. It is interesting to observe the decision of remittance-receiving households in determining investments in human capital through expenditures on education. In theory, there should be a positive impact on the demand for education for two reasons: first, the credit constraint on schooling of dependents of migrants is reduced when remittances become available, and second, the mere possibility of migration increases the incentives for investing in schooling by raising the return on education. Evidence from the Pacific tends to support this view ${ }^{5}$.

\section{Policy Implications}

In order for income distribution to become more equitable due to remittances, migration options must be extended to the poor and unskilled rather than be reserved for the highly skilled or well-off. Many of the poor lack the financial resources or social networks to migrate, so programs that explicitly target those at lower quintiles of the income distribution would yield the greatest benefits. Given social and political concerns regarding such migration it will be important to balance these benefits with recipient country concerns and this balance might be best achieved through managed migration programs designed for those who are relatively less endowed with wealth or skills. Existing literature also suggests that temporary workers remit more than permanent, and poor migrants who are not likely to travel with their families are likely to remit the most and help achieve greater social equality.

It is not clear whether policy can influence the decision to invest or consume at the household level. More importantly, it is not even clear whether that is a desirable goal at all, since remittances, by funding consumption, are providing an important social protection role for the poorest and most vulnerable sections of society. Remittances should be thought of as any other income and most households will expect to fund mostly consumption expenditures at fairly low levels of income ${ }^{6}$. As income rises, and savings and investment opportunities grow, the ability and attractiveness of saving will also grow. It may then be desirable to provide information to remittance senders and receivers on various financial instruments that are available to save and invest in. Such non-interventionist policies that remove information market asymmetries in the system are likely to be helpful in the long run in introducing households to the idea of saving. Any improvements in the business environment in recipient countries is likely to further enhance the positive impacts of remittances so this should serve as a reminder that remittances are not a substitute to carrying out structural reforms, but rather expected to be boosted by complementary reforms. 
There are proposals in some writings for matching grant schemes where public funds match remittance funds or exceed them by a factor of two or three. Such schemes are in practice in some communities in Asia and Latin America and are said to be channeling remittances into investmentlike activities and should be commended for delivering important services to the community. But from a public policy perspective it is not clear whether public resources are being diverted away from other and better uses and what the rationale is for subsidizing remittances when other forms of financial inflows are not subsidized by governments.

\section{iii) Capturing the positive externality from migration}

The economic literature has identified and recent experience has borne out that there are strong positive externalities that arise from the migration of people. The influence of the Diaspora in promoting technology transfers and knowledge networks acquired abroad by serving as "reputational intermediaries" have come to challenge the traditional 'brain drain' arguments put forth against migration from developing countries. Anecdotal and empirical evidence of this type is increasing for South Korea, Taiwan (China) and India.

However, once workers have been exposed to efficient governments and private sectors abroad they can be expected to demand an improved incentive environment domestically which would enforce greater discipline and efficiency on the allocation of internal resources from their governments and private sectors at home. A transient population of workers rotating between the remote developing regions and the developed metropolis is more likely to induce demand for better governance within the islands whilst cementing closer regional ties. This kind of "social remittances" can be a powerful vector of norm diffusion with long-term economic consequences?

But again, it's important to remind ourselves that these positive externalities may also come at a cost - after all, we are talking about people who are moving abroad, people who are absent from participating in national debates at home, people who are unable to write editorials in their national newspapers or speak on local radio stations when governments are due criticism, people who are not available to teach and mentor the next generation, and sometime not available to parent their own children. The costs on society of these absences are impossible to estimate in any economic model but are surely deeply-felt. And these costs may change depending on who migrates. If migration is skewed towards the skilled it is likely that the costs to society are greater than if the unskilled migrate. Estimates from the CGE model that experiments with a 1 percent positive change to the labor flow (skilled and unskilled) from the Pacific islands and Australia and New Zealand shows that welfare in the Pacific islands could fall due to the loss of skilled labor force and the consequent rise in real skilled wages which is not compensated for by the increased remittances sent back home ${ }^{8}$.

These monetary losses would probably increase by multiples if the long term social and institutional costs of losing skilled labor alone could be included. Workers who have invested in human capital are more likely to affect both the supply and demand for institutions. While the effect on supply of institution builders is obvious, the effect on demand is more subtle because these are the people who have the strongest interest in seeing better institutions develop as they are the ones having to make the choice to leave or stay.

At a time when institutional quality is front and center in discussions on promoting growth and development in the Pacific, it is important to understand the impact that internationally mobile human capital has on building effective institutions. Although institutions have been considered the sin qua non of development, our understanding of how successful institutions actually develop is still poor. But one could state with reasonable certainty that successful institutions depend to a large extent on having a critical mass of people with high levels of human capital and this is even more likely to be the case in the initial stages of a country's economic development.

Faini (2002) shows that migration, via remittances, contributes to growth in the migrant-sending country but is a declining function of the skilled composition of the migrant labor force. This indicates that the negative impact from brain drain may not be compensated by a larger flow of remittances, hence recommending host countries to limit their bias in immigration policies towards skilled labor. Anecdotal evidence from the Pacific seems to suggest that the loss of the very limited skilled workers poses quite a significant problem to the island countries.

\section{Policy Implications}

From a policy perspective, if social remittances are to serve an important role in transforming societies then non-elites must have the greatest access to these social remittances. A mobile pool of workers that is exposed to developed world institutions and able to bring back some of those ideas and practices home is likely to serve as a powerful agent of change. Hence migration schemes that maintain a steady inand-out of non-elite workers is likely to help achieve that most usefully.

In order to give institutions a fair chance of developing in the small islands, some balance in the immigration policies of developed nations would also be beneficial. While more balanced immigration would be fairer and better, even selected liberalization of barriers is better than no liberalization at all. Very small countries with populations of less than a couple of million, may simply lack the capabilities necessary to be able to retain talent in many sectors. Just as small towns in rich countries find it 
extremely difficult to prevent bright young people from leaving, so do small states (Pritchett, 2003). The public policy priorities for them are best directed to facilitate the movement of talent from these countries to proximate larger countries and regional integration of labor markets that can help build a critical mass of human capital. Of course, if foreign skilled labor wish to work in these small states, their entry should be encouraged rather than restricted as is, unfortunately, often the case.

But rather than remove emigration options for those lucky enough to have them, it would be better to explore ways for more people to share those gains where available.

\section{B. Migrant-receiving point of view}

\section{i) Increase in amount of resources available}

Migrant receiving developed country markets are expected to gain from inward labor mobility because their current endowments favor capital rather than labor. An influx of the scarce factor, labour, would increase the productivity and hence returns to capital. Through general equilibrium modeling it is estimated that developed countries would gain $\$ 139$ billion in real income. CGE modeling for Australia and NZ show that an increased inflow of workers from the Pacific would increase welfare of residents in these countries by $\$ 302.61$ and $\$ 26.5 \mathrm{~m}$ respectively. Output rises in all sectors in Australia and NZ, with Australia gaining most in the electronics sector and NZ in manufacturing, and both countries see large improvements in their textiles sector output. Most of these gains would come not from the movement of skilled, but rather from increases in the supply of unskilled labor. In fact, it is possible that the economic benefits of migration for developed countries could be even greater than those predicted by the models due to factors that have not been quantified such as: increased productivity of migrants and their future offspring: increased investment levels in response to higher returns to capital and possibly higher labor force participation rates among citizens of developed countries as support services become available.

Low and further declining fertility rates in many developed countries are causing higher age dependency ratios and have given rise to concerns regarding worker deficits to deliver services to a growing stock of dependants (young and old). In Australia and NZ, it is estimated that the proportion of population that is over the age of 65 is expected to more than double between the years 2004-51. The demographic projections suggest that the next 40 years will see substantial labor shortages in advanced economies (McDonald and Kippen, 2000), increasing the pressure for skilled labor as well as unskilled or semi-skilled labor in sectors not filled by domestic labour.

A variety of proposals such as increasing the retirement age and inducing more women into the workplace are being considered in developed countries. Migration is an option which would allow countries to import tax payers as well as young workers in the face of labour shortages and aging populations, but the levels of immigration required to make a dent into these problems may not be considered feasible in most countries and hence a variety of policy options will need to be considered properly to understand and prepare adequately for the future.

While migration increases the supply of labor could it drain fiscal resources? The fiscal implications of immigration are not well understood and remain difficult to quantify. While there have been attempts to estimate this for various countries, there remain challenges to properly calculating the fiscal impact of immigration because it depends heavily on: the methodology used which dictates whether the unit of analysis is the individual or the household; which expenditures and revenues are included; which public services are regarded as pure public goods; the extent of economies of scale in expenditures, the age structure of the immigrant populations and their level of skills, education and fertility. For small numbers of migrants, especially a rotating pool of migrants, it does not seem likely that the burden on resources would overshadow the large economic benefits that are estimated through the CGE model.

\section{ii) Improvement in allocation of resources}

Enhanced labor mobility can lead to an improvement in the allocation of resources by allowing a better skills-job fit in the host country's labor market. Having engineers drive taxi cabs or medical students on holiday sign up for performing farm labour reduces the overall allocative efficiency in the economy. Hence the aim of public policy should be to facilitate a more efficient allocation of human resources through flexible labour markets.

The possibilities that exist for fine-tuning migration policies to improve the fit with labor market needs through bilateral agreements are numerous and are the focus of various jobmatching programs. Indeed as labour markets tighten and the hunt for both specialist and general skills intensifies globally, receiving countries will find it in their interest to minimize the waste of scarce people resources. A serious look at the labour market outcomes for various skill intake categories and the effectiveness of job matching assistance programs would need to be reviewed.

\section{iii) Capturing the externality from migration}

While immigration may deliver tangible economic benefits to destination countries and make their populations better off for the most part, there is usually overt or inherent resistance to the idea of increased immigration in developed countries, especially of unskilled labor. The concerns expressed are either on monetary grounds such as the possibility of migrants presenting a fiscal drain on the system or taking jobs away from the domestic unskilled population; or social grounds regarding the difficulties of 
integration into destination country societies, the potential for overstaying and creating an illegal migrant underclass, or the perceived compromise to national security in an increasingly security-conscious global environment. But such security concerns can work both ways. If failed states themselves present a security concern for surrounding developed nations then any policy that reduces the fragility of these small states - and indeed, of the most vulnerable sections of these fragile states - should be considered seriously. Urdal (2004), shows that in the presence of a preponderance of a young population and low domestic employment prospects in a country, the probability of social conflict rises unless there is a safety valve of migration?

One way to minimize any fiscal or social externalities for host countries is to design a temporary movement of persons (TMP) scheme. However, not all TMP programs worldwide have been considered successful and indeed some have left lasting memories of exploitative relationships or policing of workers to enforce compliance with immigration rules, leaving destination countries wary of considering such programs again, especially for unskilled workers. Given the large potential benefits to the poor from the movement of labour, it would be a lost opportunity to let previously ill-designed schemes hold back constructive dialogue on this issue today. In fact, past experiences have much to offer by way of lessons that could usefully influence the design of new programs in the current economic context. Two main prescriptions emerge from history: the first is the need to ensure incentive compatible design so that workers are incentivized to return home at the end of the contract period. One way to ensure that incentives are properly aligned is to allow circularity of access by which good workers are allowed temporary access year after year rather than restricting access to a short finite period - often justified on the basis of equity considerations which hope to spread the gains from access to temporary overseas employment to a larger group of citizens in source countries. There are also other important criteria of incentive compatible design of TMPs and these criteria are explained at length in the World Bank's "at Home and Away' report released in 2006. The second major lesson that emerges from the past experience is the need to acknowledge and explicitly address the issue of time-inconsistency that arises from the investments made in temporary workers in the host country which later on makes it difficult to ensure temporariness and ends up undermining such schemes. Given how much the integrity of TMPs depends on ensuring temporariness I explore this further in the final section.

\section{The Bane of TMP: the time inconsistency problem and the conflict of interest between source and host countries}

This is best understood if we think of migration as a twostage game. ${ }^{10}$ Migrants enter the host country in the first stage where host country firms can choose to train the immigrants. The cost of training is mostly incurred in the first stage and hence treated as a sunk cost, however the benefit from it accrues in the second stage ${ }^{11}$. However once immigrants are trained the cost is sunk and it becomes desirable for the host to want to retain them permanently. So while firms may initially participate in such programs accepting the temporary nature of the arrangements in time period $t+1$, such an arrangement is not in their interest in time period $t+2$. This results in too much permanent migration and too little temporary migration - as has happened with numerous TMPs. For unskilled workers the social costs are considered greater than the private training costs incurred by firms so the wedge between private and socially desirable policy can be sizeable which explains the current impasse on TMP where destination countries sometimes prefer a 'no-migration' scenario altogether. In cases where the net benefit from training is small relative to the social cost (usually skilled occupations) source countries prefer temporary migration but the destination countries might prefer permanent migration. Some TMPS designed for skilled populations - like the US specialty occupation visa - are intended to be de facto permanent migration schemes where the temporary phase serves the role of screening out the non-settlers. In such a case there could be a direct conflict of interest between source and host countries who each want a different outcome from the "temporary" migration program.

The table below is an attempt to map out the possible scenarios that emerge with varying levels of private fixed costs and social costs. 
Table 1

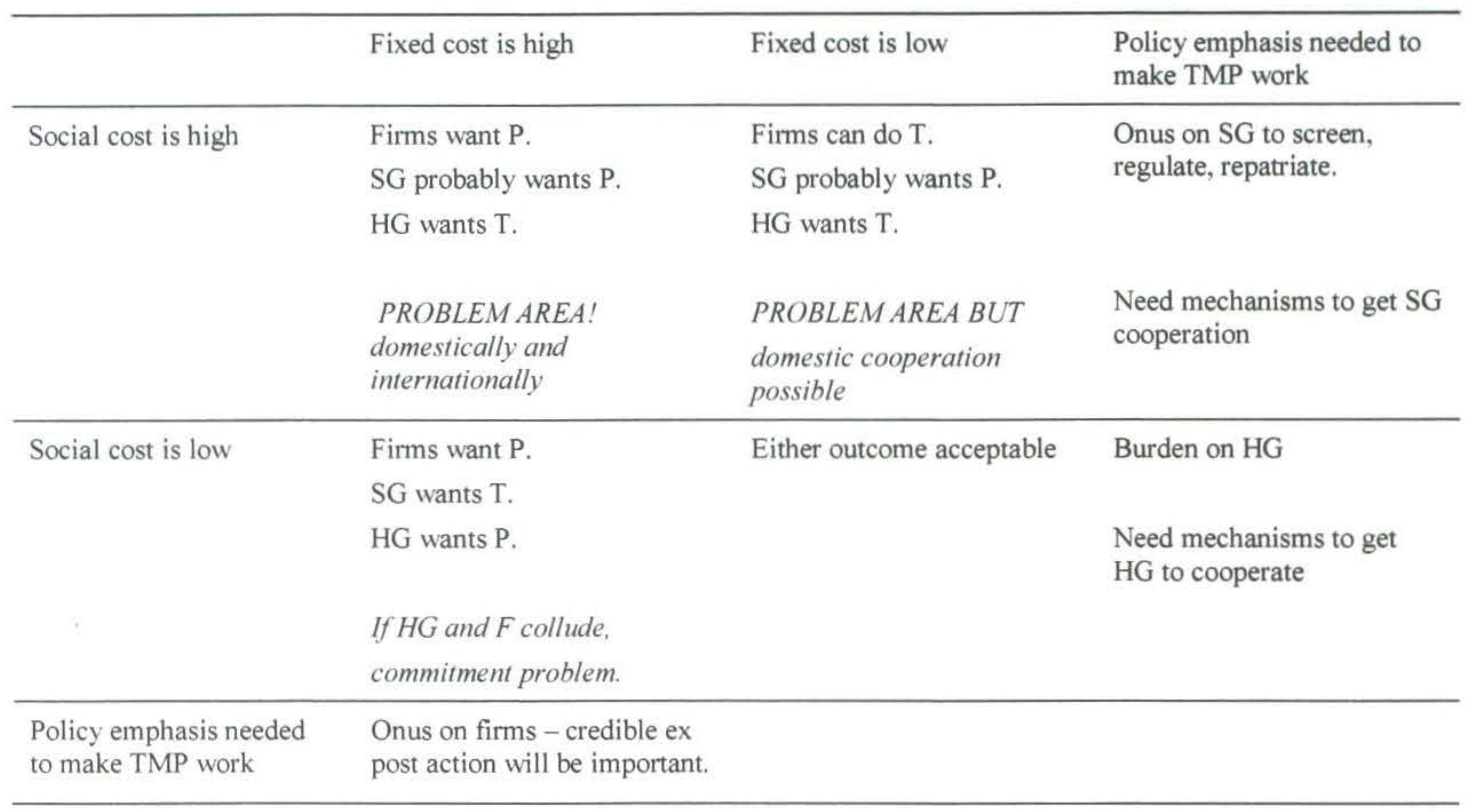

Note: Fixed $\cos \mathrm{t}=$ selection, training, travel; $\mathrm{SG}=$ source country; $\mathrm{HG}=$ host country; $\mathrm{P}=$ permanent migration; $\mathrm{T}=$ temporary migration

This initial thinking is presented in the context of Australia and New Zealand's recent participation in TMPs for the Pacific islands. Formal M\&E efforts are underway and will attempt to quantify the development impact on source countries as well as the effectiveness of accompanying facilitative measures. The above discussions provide a framework for analyzing these effects and also highlights the importance of not only getting the design right in the first place but also of staying carefully focused on the need to build mechanisms that invoke cooperation between hiring firms, workers, source and host governments. Ignoring this aspect during implementation not only risks potential domestic backlash to such immigration in host countries but seriously stymies the economic opportunities available to the region's most vulnerable populations.

\section{Notes}

1. The assumption is that the overall stock of workers in high income countries would go up by 3 percent, implying mobility of 14.2 million workers from developing to high-income countries by 2025 . Source: Global Economic Prospects, World Bank, 2005.

2. Causality with adversity at the household level is hard to establish from data usually because of the likelihood of reverse causality where remittance receiving households can mitigate adversity better (better nutrition, frequent health checks).

3. Previously collected and analysed data from Samoa is also available.

4. Or where the income effect is smaller than the substitution effect.

5. The results from the Pacific give empirical support to the above hypothesis. Primary and secondary education to age 14 in Tonga is compulsory and free. It is possibly for this reason that there was little variability in educational attainment, and the econometric analysis indicated that migration and remittance effects were not evident. In Fiji, eight years of education is supplied by the government but it is not compulsory. This probably explains why there is considerably more variation in the education attainment in the Fiji sample'. The analysis showed that remittances are associated with better educational attainment at the secondary level (by alleviating the budget constraint). In the second part of the econometric analysis the impact of household migration on post-secondary education for both Fiji and Tonga was assessed. It was found that having a migrant (rather than remittances) in the household increased the likelihood of other household members acquiring post-secondary education (by inducing 
investment in education). The relationship is stronger in Fiji where the remaining family members have an incentive to undertake further investments in education due to the size of the domestic economy and also have access to domestic education institutions in Fiji, which is less likely to be the case in Tonga. These findings are relevant from a policy perspective for they indicate that any potential negative brain-drain effects of migration could, to some extent, be countered by larger investments in education by remittance-receiving households.

6. Depending on the temporal properties of income, the mental accounting of how this income is spent could vary.

7. "Give us your Best and Brightest" (2005). Experience of the Moroccan migrants in Egypt who took on Egyptian fertility rates went against the predictions in the 1970s of demographers who were estimating a sharp decline in fertility in Egypt and only a gradual one in Morocco. Two decades later the opposite had occurred despite higher rates of economic growth and levels of education in Egypt, signalling a transfer of "values" particularly to the second generation of Moroccan-origin emigrants in Europe. Mexican data also showed how emigration can expose non-elite family members to the preferences of foreign country. A panel study of political attitudes in a cross-section of Mexico's population prior to the country's elections in 2000 questioned some 2,400 respondents about their party affiliation, their views on various political issues, and details about their families. This study revealed that those with relatives in the United States were more 'neoliberal' that those without similar connections.

8. These results are at odds with global evidence where even the movement of skilled labour increases welfare, although emigration of unskilled labour increases welfare by much more for the sending country. The difference may be emerging from the fact that in the global exercises, much of the labour movement is emerging from large developing countries that may either have an over-supply of skilled workers to start with, or can quickly make up the loss and hence attenuate the rise in wages of skilled labour.

9. In the Pacific, fertility rates are high and appear to be coming down only slowly contributing to the projected population growth of as much as 2.5 percent p.a. Even under assumptions of faster declines, significant population growth rates will continue for many years because of the population momentum that has been built up. Melanesia in particular, which is characterized by high fertility rates, low formal sector employment and very limited migration options, will generate the highest proportion of excess labor. For example, in Solomon Islands and Vanuatu where formal sector employment is already among the lowest in the region, the working age populations are expected to increase by another 30 percent within the next decade. While some domestic employment opportunities will also be created, it would still leave nearly 90 percent of the populations of these countries outside the formal sector. Estimates indicate that over 370,000 people in Fiji, 279,000 in the Solomon Islands and 129.000 in Vanuatu would not be able to find formal sector employment in their countries by 2015 .

10. Amin and Mattoo (2006)

11. Depending upon the nature of social preferences. training technology and the skill of migrants several outcomes are possible.

\section{Author}

Manjula Luthria

Senior Economist

Pacific Region

World Bank

Level 19

14 Martin Place

Sydney

NSW 2000

Australia

MLuthria@worldbank.org 